\title{
Daily Use of Salmeterol Causes Tolerance to Bronchodilation with Terbutaline in Asthmatic Subjects
}

\author{
Jimmi Elers*, Ulla Strandbygaard, Lars Pedersen and Vibeke Backer
}

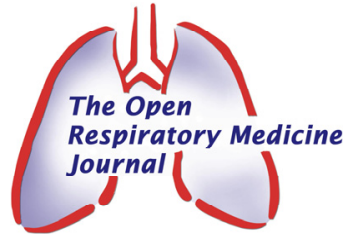

Respiratory and Allergy Research Unit, Bispebjerg Hospital, Copenhagen, Denmark

\begin{abstract}
Background: The purpose was to assess tolerance to terbutaline after daily use of long-acting $\beta 2$ - agonist (LABA) and further to evaluate two designs of reversibility test widely used in research and clinic in order to demonstrate tolerance.

Methods: Twenty-eight asthmatics were given daily LABA in 12 weeks and were randomized to challenge test and either conventional reversibility test with 2 puffs terbutaline or reversibility test with refracted doses (1 puff) every 5 min, total 4 puffs. $\mathrm{FEV}_{1}$ was measured pre-challenge, post-challenge, during and after reversibility test. All subjects had 3 visits: baseline, after 4 weeks and after 12 weeks of LABA treatment. All subjects were non-smokers, aged 18-45 years and had a positive methacholine challenge.

Results: The analyses showed a significant fall in reversibility after 4 and 12 weeks of LABA treatment $(\mathrm{p}=0.001)$ in the group with the conventional reversibility test. The group with reversibility test using refracted doses also showed a significant fall in reversibility after 4 weeks of LABA treatment $(\mathrm{p}=0.017)$ followed by a similar trend after 12 weeks $(\mathrm{p}=0.054)$, however, we experienced an interfering number of dropouts at the last visit.

Conclusion: The bronchodilator response to terbutaline was significantly reduced in asthmatic subjects using daily LABA. The tolerance develops rapidly and is present after 4 weeks of treatment. Our study showed that both the conventional reversibility test and the reversibility test with refracted doses, combined with methacholine challenge is able to demonstrate tolerance to bronchodilator after daily use of LABA.
\end{abstract}

Keywords: Tolerance, tachyphylaxis, $\beta$-2-agonist, bronchodilator, asthma.

\section{INTRODUCTION}

Long acting $\beta$-2-agonists (LABA) are used in management of moderate to severe persistent asthma to gain asthma control. It is used as add-on therapy to inhaled corticosteroids (ICS) [1], either as a fixed combination (FCICS/LABA) or in two devices, but LABA should never be used as a single drug due to the risk of serious adverse events in case of exacerbation [2]. Few studies, all with a low number of participants, have shown rapid and short lasting development of tolerance after regular use of LABA, few if any studies have shown long term development of tolerance, whereas other studies have shown significant disease control in those who had LABA added to their basic treatment with ICS [3-6].

The purpose of the present study was to assess development of tolerance to terbutaline after short and long term regular use of salmeterol and to evaluate usefulness of two designs of reversibility tests in order to demonstrate this tolerance. Reduction in lung function was induced by a methacholine challenge test, followed by a conventional reversibility test with short acting $\beta$-2-agonist (SABA) inhaling $1 \mathrm{mg}$ terbutaline and measurement of $\mathrm{FEV}_{1}$ before and 15 minutes after inhalation of terbutaline [7]. The

*Address correspondence to this author at the Respiratory and Allergy Research Unit, Bispebjerg Hospital, Bispebjerg Bakke 23, DK-2400 København NV, Denmark; Tel: +45 35313569; Fax: +45 35312179; E-mail: jele0004@bbh.regionh.dk conventional reversibility test is the most frequently used reversibility test in clinical work. Lastly, another designed reversibility test with SABA given in refracted doses followed by consecutive measurements of $\mathrm{FEV}_{1} 5$ minutes after each dose of SABA, giving a total response time of 20 minutes [8]. Because, the reversibility test with refracted doses is used in research studies we wanted to assess this design as well.

\section{MATERIAL AND METHODS}

Volunteers who responded to an advertisement in a local newspaper were invited to a screening session with assessments of fractional exhaled NO (FeNO), spirometry, methacholine challenge test, and measurement of height/weight and skin prick test. Inclusion criteria were: 1) diagnosis of asthma based on a clinical history and symptoms; 2) age between 18 to 45 years; 3) a positive methacholine challenge test with PD20 $\leq 7.8$ micromol. Exclusion criteria were: 1) other medical co-morbidities; 2) respiratory tract infections within 14 days before enrollment; 3 ) use of oral corticosteroids within the last 3 months and current smoking or history of smoking (more than 10 packyears).

Conventional reversibility test was performed with two puffs Terbutaline (total $1 \mathrm{mg}$ as dry powder) immediately after the methacholine challenge with measurement of $\mathrm{FEV}_{1}$ after 15 minutes [7]. Reversibility test with refracted doses was performed with one puff Terbutaline $(0.5 \mathrm{mg}$ as dry powder) immediately after the methacholine challenge and 
one puff after 5, 10 and 15 minutes with measurement of $\mathrm{FEV}_{1}$ at 5, 10, 15 and 20 minutes after the challenge [6, 8].

The present survey was performed as a follow-up study with three visits at week 0 (visit 0 ), 4 (visit 1 ) and 12 (visit 2). All visits included interview, measurement of FeNO, lung function, methacholine challenge test, reversibility test and at visit 0 validated questionnaires (ACQ and MiniAQLQ) [9]. Subjects received 50 micrograms salmeterol twice daily. All subjects were instructed to start treatment at visit 0 (week 0 ) and not to take medicine 12 hours before visit 1 (week 4) and visit 2 (week 12). The study medication was salmeterol/fluticasone proprionate 50+250 microgram/dose (Advair Diskus ${ }^{\circledR}$ ).

\section{ANALYSIS}

The main outcome was reversibility after methacholine challenge, expressed as the raise in $\mathrm{FEV}_{1}$ after $15 \mathrm{~min}$ at the conventional reversibility test and after $20 \mathrm{~min}$ at the reversibility test with refracted doses. Mean and standard deviations were calculated for the normally distributed data. Paired data were analyzed by paired T-tests. Values of $\mathrm{p}<0.05$ were considered statistical significant and power was set to $80 \%$. Sample size calculations were based on previous studies by using methacholine [6]. The Ethical Committee of Copenhagen, Denmark approved the study, no. H-C-20070132 and written informed consent was obtained from all participants before the first clinical examination.

\section{RESULTS}

After the screening session twenty-eight of 54 subjects were enrolled and randomized: 14 to conventional reversibility test and 14 to reversibility test with refracted doses. Seven dropouts were recorded during the study, 3 at four weeks, and 4 at 12 weeks.

Of 28 subjects randomized to the study, 13 subjects were men with 6 and 7 in each group. We found no baseline differences in mean (SD) between participants in the conventional and refracted group in age (32 (8) vs 30 (10) years respectively), $\mathrm{FEV}_{1}(3.50 \mathrm{~L}$ (0.97) vs $3.22 \mathrm{~L}$ (0.63) respectively), and $\mathrm{FEV}_{1} / \mathrm{FVC} \quad(75 \%$ (8) $v s \quad 79 \%$ (10) respectively). None of the subjects in the group with conventional reversibility test used daily ICS, while 7 subjects in the group with reversibility test with refracted doses used daily ICS. At baseline ACQ median was 1.88 and miniAQLQ median 5.48 in conventional reversibility test group and ACQ median was 1.72 and miniAQLQ 5.69 in the group with reversibility test with refracted doses.

FeNO was 41.5 ppb (visit 0), 19.1 ppb (visit 1), and 21.7 $\mathrm{ppb}$ (visit 2) in conventional reversibility test group. In the group with reversibility test with refracted doses FeNO was 32.1 (visit 0), 21.2 (visit 1), and 21.3 (visit 2).

There was no significant clinical or statistical difference in pre-challenge mean (SD) $\mathrm{FEV}_{1}$ (L) between the visits within the groups: 3.50 (0.97), 3.67 (1.05), 3.78 (0.93) respectively in conventional reversibility test vs 3.22 (0.63), $3.16(0.38), 3.19(0.28)$ respectively in the reversibility test with refracted doses.

At the three visits the mean (SD) $\mathrm{FEV}_{1}$ (L) after bronchial challenge was $2.63(0.72), 2.83(0.80), 2.93$ (0.76) respectively in the conventional reversibility test and 2.54
(0.48), $2.49(0.42), 2.50(0.36)$ respectively in reversibility test with refracted doses. This corresponds to a mean reduction in $\mathrm{FEV}_{1}$ during provocation of $0.87 \mathrm{~L}, 0.84 \mathrm{~L}, 0.85$ $\mathrm{L}$ respectively in conventional reversibility test and $0.68 \mathrm{~L}$, $0.67 \mathrm{~L}, 0.69 \mathrm{~L}$ respectively in reversibility with refracted doses, although receiving ICS treatment during a 12 weeks period.

In the group with conventional reversibility test there was a significant reduction in reversibility after methacholine challenge at visit 1 compared to visit 0 , i.e. after regular treatment with LABA with the mean difference in $\mathrm{FEV}_{1}$ after reversibility $0.56 \mathrm{~L}$ with $\mathrm{CI}(0.26-0.85)(\mathrm{p}=0.001)$. The mean difference in $\mathrm{FEV}_{1}$ after reversibility at visit 2 compared to visit 0 was $0.61 \mathrm{~L}$ with CI $(0.37-0.84)$ $(p=0.001)$. If expressed as percentage of reduction in $\mathrm{FEV}_{1}$ after reversibility the mean difference between visit 1 and 0 was $21 \%$ with $\mathrm{CI}(10-32)(\mathrm{p}=0.001)$ and between visit 2 and 0 was $24 \%$ with CI $(12-36)(\mathrm{p}=0.001)$.

We observed a significant reduction in reversibility with refracted doses after methacholine challenge at visit 1 compared to visit 0 . Mean difference in $\mathrm{FEV}_{1}$ after reversibility was $0.26 \mathrm{~L}$ with $\mathrm{CI}(0.06-0.47)(\mathrm{p}=0.017)$. There was no significant difference in reversibility at visit 2 compared to visit 0 , however, we experienced an interfering numbers of dropouts at the last visit. Mean difference was 0.28 L with CI $(-0.007-0.56)(p=0.054)$. During the study the two groups received identical medication. There is no explanation for the dropouts at the last visit in one group.

\section{DISCUSSION}

Our study has shown that regular use of salmeterol results in decreased response to terbutaline after methacholine challenge, i.e. tolerance to bronchodilator. This confirms previous findings by Hancox et al. [8-10], whom found that eight asthmatics showed development of tolerance after one week of LABA treatment. The present findings show, that giving a combination of ICS and LABA does not protect towards development of decrease in lung function during provocation, and furthermore no protection of FCICS/LABA was found towards development of tolerance during a sufficient period of treatment of 4 and 12 weeks, which confirms previous findings [10].

The new perspective in evaluation of two types of reversibility test shows that the conventional reversibility test is a valid method to detect tolerance to LABA. The conventional reversibility test is widely used in the clinical work, whereas the method mostly used in research is reversibility test with refracted doses of SABA.

In conclusion, we found that asthmatic subjects on fixed combination of ICS and LABA are in risk of developing treatment resistant decrease in lung function.

\section{ACKNOWLEDGEMENTS}

We thank all the participants for taking part of this study. The study was supported by research grant from GlaxoSmithKline.

\section{REFERENCES}

[1] Bateman ED, Hurd SS, Barnes PJ, et al. Global strategy for asthma management and prevention: GINA executive summary. Eur Respir J 2008; 31: 143-78. 
[2] Lazarus SC. Long-acting beta2-agonist monotherapy vs continued therapy with inhaled corticosteroids in patients with persistent asthma: a randomized controlled trial. JAMA 2001; 20: 2583-93.

[3] Pauwels RA, Lofdahl CG, Postma DS, et al. Effect of inhaled formoterol and budesonide on exacerbations of asthma. Formoterol and Corticosteroids Establisning Therapy (FACET) International Study Group. N Engl J Med 1997; 337: 1405-11.

[4] Ni CM, Greenstone I, Danish A, et al. Long-acting beta2-agonists versus placebo in addition to inhaled corticosteroids in children and adults with chronic asthma. Cochrane Database Syst Rev 2005; CD005535.

[5] Bateman ED, Boushey HA, Bousquet J, et al. Can guidelinedefined asthma control be achieved? The gaining optimal asthma control study. Am J Respir Crit Care Med 2004; 170: 836-44.
[6] Hancox RJ, Taylor DR. Long-acting beta-agonist tratment in patients with persistent asthma already receiving inhaled corticosteroids. Bio Drugs 2001; 15: 11-24.

[7] The Global Strategy for Asthma Management and Prevention. Global Initiative for Asthma Web site [Internet]. USA: Global Strategy for Asthma Management and Prevention. Available from www.ginasthma.org, 2008.

[8] Haney S, Hancox RJ. Tolerance to bronchodilation during treatment with long-acting beta-agonists, a randomised controlled trial. Respir Res 2005; 6: 107.

[9] Juniper EF, O'Byrne, PM, Guyatt, GH, Ferrie, PJ, King, DR. Development and validation of a questionnaire to measure asthma control. Eur Respir J 1999; 14: 902-7.

[10] Haney S, Hancox RJ. Rapid onset of tolerance to beta-agonist bronchodilation. Respir Med 2005; 99: 566-71.

(C) Elers et al.; Licensee Bentham Open.

This is an open access article licensed under the terms of the Creative Commons Attribution Non-Commercial License (http://creativecommons.org/licenses/ by-nc/3.0/) which permits unrestricted, non-commercial use, distribution and reproduction in any medium, provided the work is properly cited. 